\title{
Social support and social security issues of elders in Sri Lanka
}

\author{
Perera Bilesha \\ Department of Community Medicine, Faculty of Medicine, University of Ruhuna, Galle, Sri Lanka
}

Correspondence to: Dr. Bilesha Perera (pperera@indiana.edu)

\begin{abstract}
With decreasing fertility and mortality rates, the population of Sri Lanka is rapidly aging, and this issue will become one of the greatest challenges the government has to face in the near future. A considerable proportion of elders in Sri Lanka depends on their children or relatives for food, shelter and safely. Although caring for elders is an integral and important cultural norm in the country, factors such as urbanization, migration and westernization have meant that many elders today experience poor health and living conditions. In this context, social support and social security of elders are important issues and need urgent attention of the government, non-governmental organizations and general public. Social support and social security systems available today for elders in Sri Lanka need to be investigated thoroughly to identify mechanisms and strategies that are effective and sustainable. Further, unmet needs of elders with respect to social support and social security need to be assessed. Based on such investigations, specific plans of actions should be formulated to reduce future social support and social security problems of elders in Sri Lanka.
\end{abstract}

Key words : Aging, social support, social security

\section{Introduction}

Substantial declines in both fertility and mortality rates in Sri Lanka have led to an unprecedented aging of its population (1-3). In 1981, the crude birth rate in Sri Lanka was 28.2 per 1000 population, and in 2009, the figure was 16.2 per 1000 population. In 1981, the crude death rate in Sri Lanka was 7.4 per 1000 population, and in 2009 the figure was 6.1 per 1000 population. In 2001, $10.0 \%$ of the Sri Lankan population consisted of elders (aged over 60 years), and it is estimated that by the year 2031,22.0\% will be elders (4).

Like many other countries, life expectancy at birth for females in Sri Lanka is greater than that of males. The gap between male and female life expectancy is expected to be slightly growing in the coming decades (4). During the period 1991-1996, life expectancy at birth was 69.5 years for males and 74.2 years for females. Thus the difference was 4.7 years. For the period 2026-2031, life expectancy at birth will be 75.8 years for males and 80.9 years for females, and the difference will be 5.1 years. The geriatric population in Sri Lanka in the coming decades would consist of a higher proportion of females. Many women tend to marry men older than themselves, and therefore women are much more likely to be living alone in their old age than men. Thus, women are more vulnerable than men to experience economic and socio-cultural hardships associated with old age. Further, in 2001, the old age dependency ratio (number of elders divided by number of people aged 15-60) in the country was $10.1 \%$ and it is expected to increase to $24.4 \%$ by 2031. Current evidence suggest that health and maintaining cost of older people is higher than that of younger dependents and therefore population aging will become a major socio-economic issue in Sri Lanka in the near future $(5,6)$.

In fact, Sri Lanka is one of the fastest aging countries in the world. This demographic transition has occurred simultaneously with profound social, economic, cultural and environmental changes that do not favor traditional forms of care and support. Thus, the implications of aging of the population in Sri Lanka for providers of services are considerable and challenging $(7,8)$. Although elders are not always ill, as they age their physical, psychological, emotional and abilities to cope up adequately with people and the environment deteriorate. Poor vision impaired hearing, deterioration in the ability to cope adequately with daily functions, heart diseases, diabetes, cancers and cognitive impairment are the 
prevalent diseases and ill-health conditions found among the elders in Sri Lanka (9-11). Further, emotional and relationship problems make many elders psychologically unhealthy. There is a severe shortage of geriatricians and geriatric health care workers in Sri Lanka, and the morbidity level of the elderly population is significantly higher than the national average.

Given that most elders today are self-employed and do not have any formal financial support, many are dependant on their children or other relatives for food, shelter and safety $(8,12)$. This situation may not change significantly in the near future. Thus, Sri Lanka urgently requires economic and social strategies for dealing with problems associated with old age.

In Sri Lanka traditional obligations of children towards their parents seem to diminish with emerging changes in the family structures. Younger generations move out of their parents' houses to work and live in distant locations for their future prospects. Thus, urbanization, migration and higher level of female participation in the labor force have reduced the support previously provided by extended families to elders $(8,12,13)$. Many socio-economic and basic infrastructural problems such as transport and accessibility to proper health care services, affect the elderly disproportionately and many urban as well as rural elders become socially isolated and neglected. Thus, in the Sri Lankan context, it is very possible that the most important emerging themes in relation to gerontology are social support and social security.

\section{Social support}

Elders greatly benefit from social relations. Lack of social relationship is a strong determinant of morbidity in the old age. Social interactions help elders in many ways. Involvements in activities such as nurturing the children, visiting friends and relations, pilgrimages, performing community services and attending religious activities all make elders content, engaged and physically and mentally active $(12,14,15)$. Social networking is the grouping of individuals or organizations to gather and share information and experiences about community and personal activities such as organizing a festival or ceremony, cooking and gardening, developing friendships or professional alliances, political activities and finding employment or volunteer work. Considerable empirical research substantiates the importance of social networks on health and well-being in later life. Elders with supportive housing and environment have better psychological health and tend to use significantly more informal supports when in need. Various researches support' the notion that people who keep active and participate in family and community activities have greater chances of experiencing a healthy life.

However, in some studies it is observed that visiting relatives and friends or participating in community activities declines gradually with increasing age resulting negative consequences for elders (16). Less social interaction decreases the overall health of the elders. In one study, it was observed that elders do not go to temples frequently contrasting to what the general public believes. Active aging, a relatively new approach to increase the quality of life of elders, emphasises the importance of engagement in physical activities to gain health in old age. Recognizing the importance of active aging, the government has recently instructed each AGA division in the country to form elderly societies with the goal of making elders more active (17). Participation in community activities and group recreational activities such as pilgrimages are organized by these societies.

Showing respect and taking care of elders have been considered normal behaviors in the Sri Lankan context. Children living in different locations support their elderly parents with remittances and materials, and by regular visits and contacts. However, friends are the most important relational ties with respect to similar interests, companionship, and health-promoting practices. Emotional support by children, relatives and by friends is one of the important dimensions of socially supportive systems. Also, emotional support has been found to be the most strongly and consistently related factor to health conditions of elders. Receiving instrumental support may not have such an explicit impact.

\section{Social security systems}

Elders in many countries are entitled to some form of auxiliary living support. With the increasing life expectancy in Sri Lanka, the number of elders to be supported will gradually increase. Traditionally, cultural norms and values were such that nurturing 
the elderly was a family obligation. The majority of elders in Sri Lanka are living in rural areas and their income was mainly based on agricultural products and related occupations $(8,17)$. Social gatherings and cultural events that originally based were on agricultural events which provided elders a place to enjoy life with others. However, after 1980's with the introduction of the open economy, younger people moved towards industrial work and there was an outward migration from rural areas. Thus, the traditional values and occupations related to agriculture eroded and today there is an urgent need to establish and maintain social security systems to support elders.

Prior to 1958 , there were only a few social security systems in Sri Lanka and those in existence were confined to small proportion of privileged people; for example Public Servants Pension Scheme (17). After 1958 certain social security schemes emerged targeting semi-government and private sector employees such as Employees Provident Fund Act and Employees Trust Fund. However, a very limited number of people benefited from those schemes as the majority (about 70\%) of the employed were selfemployees. Realizing this fact, the government has introduced three contributory social security pension schemes for farmers, fishermen and other selfemployed. The three schemes are all voluntary and contributory with some contributions from the government. The benefits under the schemes are in the form of a monthly pension for life after age of 60 . In addition, the government has introduced schemes to grant financial assistance to very poor people. Public Assistance Monthly Allowance scheme and the Financial Assistance Schemes for patients suffering from chronic diseases are two of them. Most of the beneficiaries under these schemes are older persons. During the last two decades many government owned and private banks and insurance companies have introduced social security schemes known as market based social security schemes. All of these are on a voluntary contributory basis. Most of these schemes target moderate and high income groups, thus, many of the low-income groups still have to depend on government support in their old age. There are deficiencies in most of these schemes so that the large number of elders in the future may not be able to get sufficient support. Thus, there is a need to reconsider government policies and usefulness of available schemes to protect elders from future economic hardships.

\section{Discussion}

The population in Sri Lanka is rapidly aging. As a middle income, agricultural country, Sri Lanka is already challenged by this public health issue. Social support systems for elders in Sri Lanka are not well studied. Family connectedness and participation in community activities by elders and how village based elderly societies group together and work together at regional level and what factors are associated with such mechanisms are not known. The social structures and social processes that influence these social networks need to be further investigated.

Given that the majority of elders in the country are self-employed, agricultural workers, the existing social security systems appear not sufficient to meet the elders financial needs since most of these schemes are targeted at public and private sector employees. The government has to initiate a dialog including all stakeholders: health professionals, economists, sociologists, educationists and politicians, and not least the elderly themselves to make effective public health policy and actions.

\section{References}

1. Department of Census and Statistics. Population and Housing. Retrieved from http://www. Statistics.gov.lk/ popHouStat/vitalStatistics/Tables.asp on 14 February, 2011.

2. Ministry of Health. Annual Health Bulletin Sri Lanka 2007, Ministry of Health, Colombo, 2007.

3. Ministry of Health, Annual Health Bulletin Sri Lanka 1983, Ministry of Health, Colombo, 1983.

4. De Silva W. I. Population Projections for Sri Lanka: 19912041, Institute of Policy Studies, Colombo, 1997.

5. Abeykoon ATPL. Aging and the health sector in Sri Lanka. Ceylon Medical Journal, 2000, 45: 52-4.

6. Perera, B. Health of our elders. Ceylon Medical Journal, 1997, 42: 91-3.

7. Abeykoon ATPL. Demographic implications of health care in Sri Lanka. Asia-Pacific Population Journal, 1996, 11: $47-8$

8. De Silva W.I. Family transition in south Asia: Provision of social services and social protection. Asia-Pacific Population Journal, 2005, 20(2): 13-6. 
9. Balasuriya S, Nugegoda DB. Health aspects of an urban elderly population. Ceylon Medical Journal, 1993, 38; 29-30.

10. Mendis N, Illesinghe I. Health and social aspects of the Elderly. Ceylon Medical Journal, 1989, 34, 95-8.

11. Nugegoda DB, Balasooriya S. Health and Social status of an elderly urban population in Sri Lanka, Social Science and Medicine, 1995, 40(4); 437-42.

12. Fernando DN. Support for the elderly in Sri Lanka, World Health Forum, 1995, 16, 1363.

13. Andrews GR. (eds). Aging in south Asia: a five country study, WHO, New Delhi, 1993.
14. Cairney J, Arnold R. Social class, health and aging: socioeconomic determinants of self-reported morbidity among the non-institutionalized elderly in Canada. Canadian Journal of Public Health 1996, 87: 199-203.

15. Marmot M, Wilkinson L. (eds.) Social Determinants of Health. Oxford University Press, Oxford, UK, 2006.

16. Uhlenberg P. International handbook of population aging, Springer, Heidelberg, Germany, 2009.

17. Jegarasasingam V, Karunarathne G. Seminar on the social, health and economic consequences of population aging in the context of changing families-Country report Sri Lanka, UNFPA, Bangkok, Thailand, 2007. 